\title{
GnRH-dependent precocious puberty manifested at the age of 14 months in a girl with $47, X X X$ karyotype
}

\author{
Nicos Skordis, ${ }^{1,2,3}$ Eleana Ferrari, ${ }^{2}$ Aria Antoniadou, ${ }^{2}$ Leonidas A. Phylactou, ${ }^{3}$ \\ Pavlos Fanis, ${ }^{3}$ Vassos Neocleous ${ }^{3}$
}

${ }^{1}$ Division of Pediatric Endocrinology, Paedi Center for specialized Pediatrics, Nicosia, ${ }^{2}$ St George's, University of London Medical School at the University of Nicosia, ${ }^{3}$ Department of Molecular Genetics, Function \& Therapy, The Cyprus Institute of Neurology \& Genetics, Nicosia, Cyprus

\begin{abstract}
This case report describes a 47,XXX girl who presented very early, at the age of 14 months, with signs of sexual precocity (breast and pubic hair development, menarche) and was finally diagnosed with GnRH dependent precocious puberty with no evidence of underlying central nervous system pathology. Molecular testing did not identify any genetic defect in any of the genes tested (KISS1, KISS1R, DLK1 and the intronless MKRN3). Though previous studies have shown a link between karyotype $47, \mathrm{XXX}$ and precocious puberty, this is the youngest patient reported so far. Treatment with GnRH analog was commenced and proved to be effective, indicating a successful suppression of the hypothalamic-pituitary-ovarian axis.
\end{abstract}

Key words: GnRH, 47,XXX karyotype, Precocious puberty

\section{INTRODUCTION}

Precocious puberty is defined as the development of secondary sexual characteristics before the age of 8 years in girls and 9 years in boys and results either from the activation of the hypothalamic-pituitary-gonadal (HPG) axis [gonadotropin-dependent precocious puberty (GDPP)] or by the autonomous secretion of sex steroids by the gonads or the adrenal glands [gonadotropin-independent precocious puberty (GIPP)]. ${ }^{1,2}$

\footnotetext{
Address for correspondence:

Nicos Skordis, MD, PhD, Division of Pediatric Endocrinology, Paedi Center for Specialized Pediatrics, 178 Athalassas Ave., 2025 Nicosia, Cyprus; Tel.: +357 22465880, Fax: +357 22

515265, E-mail: nicosskordis@paedi.org.cy

Received: 04-04-2017, Accepted: 24-05-2017
}

Trisomy X, otherwise known as $47, \mathrm{XXX}$, is a common sex chromosomal abnormality that results in abnormal separation of the $\mathrm{X}$ chromosome during cell division. It was first reported in 1959 by Jacobs. ${ }^{3}$ At birth, 47, XXX girls have a low birth weight with relatively small head circumference and the diagnosis is usually not suspected. ${ }^{4}$ Until puberty they demonstrate accelerated growth and have a tendency to be tall and thin, although many patients appear to be normal. Although in adulthood most 47, XXX females seem to have normal ovarian function and fertility, various studies have demonstrated premature ovarian failure and oligomenorrhea to be more prevalent than in controls. ${ }^{4,5}$

The overall incidence of precocious puberty is estimated to be $1: 5,000$ to $1: 10,000$ children, ${ }^{6}$ while 
the incidence of $47, \mathrm{XXX}$, which is the most common female chromosomal abnormality, occurs in approximately 1 in 1,000 female births. ${ }^{7}$ Clinical characteristics of 47,XXX girls include epicanthal folds, hypertelorism, upslanting palpebral fissures, clinodactyly, overlapping digits and pectus excavatum. The majority of cases are asymptomatic with normal pubertal onset and sexual development. ${ }^{8}$

Although girls with 47,XXX karyotype have a dysregulated HPG axis, there is only one report in the literature of a girl bearing this karyotype and manifesting precocious puberty as early as at the age of 6.8 years. ${ }^{9}$ The case reported here describes a girl with 47, XXX karyotype who presented with precocious puberty and menarche at a much earlier age.

\section{CASE REPORT}

This female child presented with breast and pubic hair development with vaginal mucus discharge at the age of 14 months. She was a full term baby, delivered vaginally following an uneventful spontaneous pregnancy, with a birth weight of $3.086 \mathrm{Kg}$. No dysmorphic features were noted and developmental milestones were appropriate for age. Growth acceleration was observed based on her growth charts. Family history was otherwise unremarkable with no evidence of sexual precocity in either the parents or siblings.

Initial investigation, as depicted in Table 1, was compatible with GnRH-dependent precocious puberty, as there was an exaggerated response of LH to the LHRH test. Thyroid function and adrenal androgens were within normal limits. Ultrasound (US) of the breasts and the adrenals exhibited no morphological changes but both uterus and ovaries were enlarged, as seen in Table 2. MRI of the pituitary hypothalamic area revealed no pathology except for the presence of a pituitary microadenoma. The request for chromosomal analyses, which was based on the observed baseline increased levels of both FSH and LH (Table 1), finally identified a 47,XXX karyotype.

During follow-up, the child initially demonstrated breast regression but subsequently showed rapid pubertal progression with obviously oestrogenized vagina and menstrual bleeding. Cytology of a vaginal

Table 1. Serial hormonal investigation

\begin{tabular}{|c|c|c|c|c|c|c|c|c|}
\hline \multirow[t]{2}{*}{ Age } & \multirow{2}{*}{$\begin{array}{c}\text { Way of } \\
\text { measurement }\end{array}$} & \multicolumn{3}{|c|}{ FSH (IU/L) } & \multicolumn{3}{|c|}{ LH (IU/L) } & \multirow{2}{*}{$\begin{array}{c}\text { Oestradiol } \\
(\mathrm{pg} / \mathrm{ml})\end{array}$} \\
\hline & & $0 \mathrm{~min}$ & $30 \mathrm{~min}$ & $60 \mathrm{~min}$ & $0 \mathrm{~min}$ & $30 \mathrm{~min}$ & $60 \mathrm{~min}$ & \\
\hline 14 months & LHRH test & 2.06 & 16.55 & 16.52 & 0.81 & 84.74 & 55.91 & 40 \\
\hline 20 months & LHRH test & 5.44 & 13.31 & 14.92 & 1.65 & 33.05 & 26.32 & 25 \\
\hline 2 years & Baseline & & 11.35 & & & 15.15 & & $<5$ \\
\hline 2.2 years & LHRH test & 1.47 & 7.04 & 8.35 & 0.57 & 35.76 & 33.29 & 100.0 \\
\hline \multicolumn{9}{|c|}{ Treatment with GnRH analog } \\
\hline 3 years & Baseline & & 1.46 & & & 1.23 & & $<5$ \\
\hline
\end{tabular}

Table 2. Uterus, endometrium and right and left ovary measurements

\begin{tabular}{|c|c|c|c|c|c|c|c|}
\hline \multirow[t]{2}{*}{ Age } & \multirow[t]{2}{*}{ Uterus (cm) } & \multirow{2}{*}{$\begin{array}{l}\text { Fundus to } \\
\text { cervix ratio }\end{array}$} & \multirow{2}{*}{$\begin{array}{c}\text { Endometrial } \\
\text { Thickness } \\
\text { (mm) }\end{array}$} & \multicolumn{2}{|c|}{ Right ovary } & \multicolumn{2}{|c|}{ Left ovary } \\
\hline & & & & $\begin{array}{l}\text { Dimensions } \\
\text { (cm) }\end{array}$ & $\begin{array}{c}\text { Volume } \\
\text { (cm) }\end{array}$ & $\begin{array}{l}\text { Dimensions } \\
(\mathrm{cm})\end{array}$ & $\begin{array}{l}\text { Volume } \\
\text { (cm) }\end{array}$ \\
\hline 14 months & $4.08 \times 2.07 \times 1.00$ & $1.19 / 0.97$ & Not visible & $1.57 \times 0.78 \times 1.17$ & 0.750 & $1.48 \times 0.99 \times 1.18$ & 0.900 \\
\hline 20 months & $3.70 \times 2.00 \times 1.40$ & $1.7 / 1$ & 3.00 & & 0.800 & & 0.800 \\
\hline 2.2 years & $4.40 \times 2.60$ & $2 / 1$ & 6.50 & $1.50 \times 0.85 \times 1.30$ & 0.850 & $1.45 \times 1.55 \times 1.50$ & 1.750 \\
\hline \multicolumn{8}{|c|}{ Treatment with GnRH analog } \\
\hline 3 years & $3.60 \times 1.00$ & $1 / 1$ & 0.80 & $1.35 \times 0.40 \times 1.00$ & 0.265 & $1.00 \times 0.60 \times 0.90$ & 0.275 \\
\hline
\end{tabular}


smear displayed normal epithelial cells, negative for malignant cells, with a maturation index consistent with high oestrogen status. Cancer markers were normal. A repeated LHRH test at the age of 2.2 years confirmed the diagnosis of GDPP. Following the results of the test and the clinical progression, the girl was started on treatment with GnRH analog with excellent results. She had no further vaginal bleeding and breast tissue regressed. Informed consent from the parents of the minor was obtained in accordance with the national laws.

\section{Molecular studies}

Genomic DNA isolated from a peripheral blood sample of the patient was examined by Sanger sequencing for potential sequence variations in the KISSI (ENST00000367194), KISSIR (ENST00000234371), DLK1 (ENST00000341267) and the intronless MKRN3 gene (ENST00000314520). The PCR products of all coding regions of the above genes were analysed on an ABI 3130XL apparatus (Applied Biosystems, Waltham, MT, USA). All performing conditions and primers used for the PCR analyses of the KISS1, KISSIR and DLKI genes can be provided upon request. The methodology and PCR conditions for the $M K R N 3$ gene were the same as that reported in previous work by our group. ${ }^{10,11}$ No mutation was identified in the coding region of any of the above genes, thus our investigation continued with chromosomal analyses.

\section{DISCUSSION}

Triple $\mathrm{X}$ syndrome is a common sex chromosome aneuploidy where the extra $\mathrm{X}$ chromosome is the result of nondisjunction in oogenesis and therefore it has a maternal origin. ${ }^{12}$ Females with 47,XXX karyotype often have menstrual irregularities which include: delayed menarche, oligomenorrhea and premature ovarian failure. ${ }^{4}$ The manifestation of GDPP in females with triple $\mathrm{X}$ syndrome was first reported in a 6.2 year old girl who presented with breast development and pubic hair growth; however, no vaginal discharge or spotting were noted. ${ }^{9}$

The herein reported case had evidence of dysregulation of the HPG axis, which was based firstly on its very early and exaggerated activation and secondly the abnormally elevated basal levels of FSH and LH found incidentally at the age of 2 years. A recent report by Stagi et al, 2016, noted that girls with 47,XXX manifest puberty at an earlier age compared to the normal population. In their series, 2/15 girls studied showed a LHRH stimulation test consistent with GDPP and 3/15 presented with clinical signs of sexual precocity. In none of their patients did the baseline levels of FSH and LH increase. FSH baseline levels ranged from 0.99 to $7.73 \mathrm{IU} / \mathrm{L}$ and those of $\mathrm{LH}$ from 0.25 to $3.02 \mathrm{IU} / \mathrm{L}$. Relatively high FSH levels were found in three girls, who were more than 10 years of age, suggesting blunted ovarian function. ${ }^{5}$ Elevated basal FSH (18.6 IU/L) and LH (2.3 IU/L) levels with normal oestradiol levels, in the absence of pubertal signs, were reported in a 4-year old girl with nonmosaic 47,XXX karyotype, indicating premature activation of the GnRH pulse generator. ${ }^{13}$

The pathogenesis of pubertal disorders in most chromosomal aneuploidies is still a mystery. The alterations in the hypothalamic feedback system could be attributed to blunted ovarian function which augments the secretion of gonadotrophins. Impaired ovarian function in girls with 47,XXX is widely demonstrated and it is mostly manifested well after adolescence with premature menopause. The increased levels of gonadotrophins found in our patient at the early age of 2 years could be attributed to a combination of early activation of the HPG axis and relatively blunted ovarian function.

Early activation of the HPG axis could be attributed to the existence of the extra $\mathrm{X}$ chromosome and the expression of genes which had escaped $\mathrm{X}$ inactivation. Such genes are potential contributors to sexually dimorphic traits and are expressed in variable phenotypes in females heterozygous for X-linked conditions. In a similar fashion, genes which escape $\mathrm{X}$ inactivation may also contribute to clinical abnormalities in patients with abnormal X chromosomes. ${ }^{14}$

In conclusion, the girl with triple $\mathrm{X}$ syndrome reported here manifested very early and exaggerated premature activation of the GnRH pulse generator, which resulted in clinical signs of sexual maturation and the manifestation of menstrual bleeding. The effectiveness of treatment with GnRH analog in su- 
pressing both clinical signs and hormonal findings further corroborates the activation of the HPG axis as being the underlying pathogenetic mechanism.

\section{CONFLICT OF INTEREST STATEMENT}

The authors have nothing to declare.

\section{REFERENCES}

1. Carel J-C, Leger J, 2008 Clinical practice. Precocious puberty. N Engl J Med 358: 2366-2377.

2. Fuqua JS, 2013 Treatment and outcomes of precocious puberty: an update. J Clin Endocrinol Metab 98: 21982207.

3. Jacobs PA, Baikie AG, Brown WM, et al, 1959 Evidence for the existence of the human "super female". Lancet 2: 423-425.

4. Otter M, Schrander-Stumpel CT, Curfs LM, 2010 Triple X syndrome: a review of the literature. Eur J Hum Genet 18: 265-271.

5. Stagi S, di Tommaso M, Scalini P, et al, 2016 Triple $\mathrm{X}$ syndrome and puberty: focus on the hypothalamushypophysis-gonad axis. Fertil Steril 105: 1547-1553.

6. Partsch CJSippell WG, 2001 Pathogenesis and epidemiology of precocious puberty. Effects of exogenous oestrogens. Hum Reprod Update 7: 292-302.

7. Tartaglia NR, Howell S, Sutherland A, Wilson R, Wilson L, 2010 A review of trisomy X (47,XXX). Orphanet J Rare Dis 5: 8.

8. Cordts EB, Christofolini DM, Dos Santos AA, Bianco B, Barbosa CP, 2011 Genetic aspects of premature ovarian failure: a literature review. Arch Gynecol Obstet 283: 635-643.

9. Grosso S, Anichini C, Berardi R, et al, 2000 Central precocious puberty and abnormal chromosomal patterns. Endocr Pathol 11: 69-75.

10. Neocleous V, Shammas C, Phelan MM, et al, 2016 In silico analysis of a novel MKRN3 missense mutation in familial central precocious puberty. Clin Endocrinol (Oxf) 84: 80-84.

11. Christoforidis A, Skordis N, Fanis P, et al, 2017 A novel MKRN3 nonsense mutation causing familial central precocious puberty. Endocrine 56: 446-449.

12. May KM, Jacobs PA, Lee M, et al, 1990 The parental origin of the extra X chromosome in 47, XXX females. Am J Hum Genet 46: 754-761.

13. Li M, Zou C, Zhao Z, 2012 Triple x syndrome with short stature: case report and literature review. Iran J Pediatr 22: 269-273.

14. Carrel L, Willard HF, $2005 \mathrm{X}$-inactivation profile reveals extensive variability in $\mathrm{X}$-linked gene expression in females. Nature 434: 400-404. 